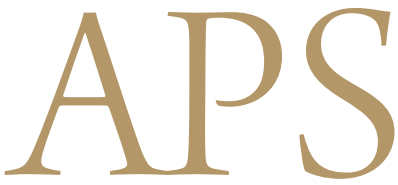

Archives of Plastic Surgery

\title{
Face Reconstruction Using Lateral Intercostal Artery Perforator-Based Adipofascial Free Flap
}

\author{
Jae Hoon Jeong ${ }^{1}$, Jin Myung Hong ${ }^{2}$, Nobuaki Imanishi ${ }^{3}$, Yoonho Lee ${ }^{2}$, Hak Chang ${ }^{2,4}$ \\ ${ }^{1}$ Department of Plastic and Reconstructive Surgery, Seoul National University Bundang Hospital, Seongnam; ${ }^{2}$ Department of Plastic and \\ Reconstructive Surgery, Seoul National University College of Medicine, Seoul, Korea; ${ }^{3}$ Department of Anatomy, Keio University College of \\ Medicine, Tokyo, Japan; ${ }^{4}$ Ischemic/Hypoxic Disease Institute Seoul National University College of Medicine, Seoul, Korea
}

Background The aim of this study was to determine the efficacy of lateral intercostal artery perforator-based adipofascial free flaps for facial reconstruction in patients with facial soft tissue deficiency.

Methods We conducted a retrospective study of five consecutive patients diagnosed with facial soft tissue deficiency who underwent operations between July 2006 and November 2011. Flap design included the area containing the perforators. A linear incision was made along the rib, which had the main intercostal pedicle. First, we dissected below Scarpa's fascia as the dorsal limit of the flap. Then, the adipofascial flap was elevated from the medial to the lateral side, including the perforator that pierces the serratus anterior muscle after emerging from the lateral intercostal artery. After confirming the location of the perforator, pedicle dissection was performed dorsally.

Results Dominant perforators were located on the sixth to eighth intercostal space, and more than four perforators were found in fresh-cadaver angiography. In the clinical case series, the seventh or eighth intercostal artery perforators were used for the free flaps. The mean diameter of the pedicle artery was $1.36 \mathrm{~mm}$, and the mean pedicle length was $61.4 \mathrm{~mm}$. There was one case of partial fat necrosis. No severe complications occurred.

Conclusions This is the first study of facial contour reconstruction using lateral intercostal artery perforator-based adipofascial free flaps. The use of this type of flap was effective and can be considered a good alternative for restoring facial symmetry in patients with severe facial soft tissue deficiency.

Keywords Perforator flap / Free tissue flaps / Face
Correspondence: Hak Chang Department of Plastic and Reconstructive Surgery, Seoul National University College of Medicine, 101 Daehak-ro, Jongno-gu, Seoul 110-744, Korea

Tel: +82-2-2072-3086

Fax: +82-2-741-5130

E-mail: prshchang@gmail.com

\begin{abstract}
This research was supported by the Basic Science Research Program through the National Research Foundation of Korea (NRF) funded by the Ministry of Education, Science and Technology (R11-2005-065).

This study was presented at the 70th Congress of the Korean Society of Plastic and Reconstructive Surgeons, on November 2012 in Seoul, Korea and was presented at the 3rd Research and Reconstructive Forum, on May 2013 in Daegu, Korea.
\end{abstract}

No potential conflict of interest relevant to this article was reported.

Received: 29 Jul 2013 • Revised: 11 Sep 2013 • Accepted: 20 Sep 2013

pISSN: 2234-6163 • elSSN: 2234-6171 • http://dx.doi.org/10.5999/aps.2014.41.1.50 • Arch Plast Surg 2014;41:50-56

\section{INTRODUCTION}

The intercostal vessels constitute an arcade between the aorta and the internal mammary vessels. Furthermore, many perforators originate from the intercostal artery. Among those, the lateral intercostal artery perforator pierces the serratus anterior muscle in front of the anterior border of the latissimus dorsi muscle after emerging from the costal segment of the lateral intercostal artery $[1,2]$.

The versatility of the intercostal neurovascular pedicle to supply a skin-muscle flap was first reported in 1931 [3]. However, the clinical application of intercostal vessel-based flaps was not 
understood before anatomical studies by Kerrigan and Daniel [4], who studied intercostal myocutaneous flaps with random extensions beyond the thoracic cage. The lateral intercostal fasciocutaneous free flap based on a neurovascular bundle sparing the abdominal musculature, a perforator-based intercostal free flap, was first described by Badran et al. [5]. Until recently, most reported cases of intercostal perforator flaps were used for breast and lumbosacral defect reconstruction [1,6-12]. The aim of this study was to determine the efficacy of lateral intercostal artery perforator-based adipofascial free flaps for facial soft tissue re-

Fig. 1. Preoperative multidetector computerized tomography imaging

(A, B) Some patients underwent multidetector computed tomography imaging to evaluate the lateral intercostal artery perforators (white arrows). (C, D) The dominant perforator was identified, and its piercing location was measured from the anterior superior iliac spine and from the umbilicus.
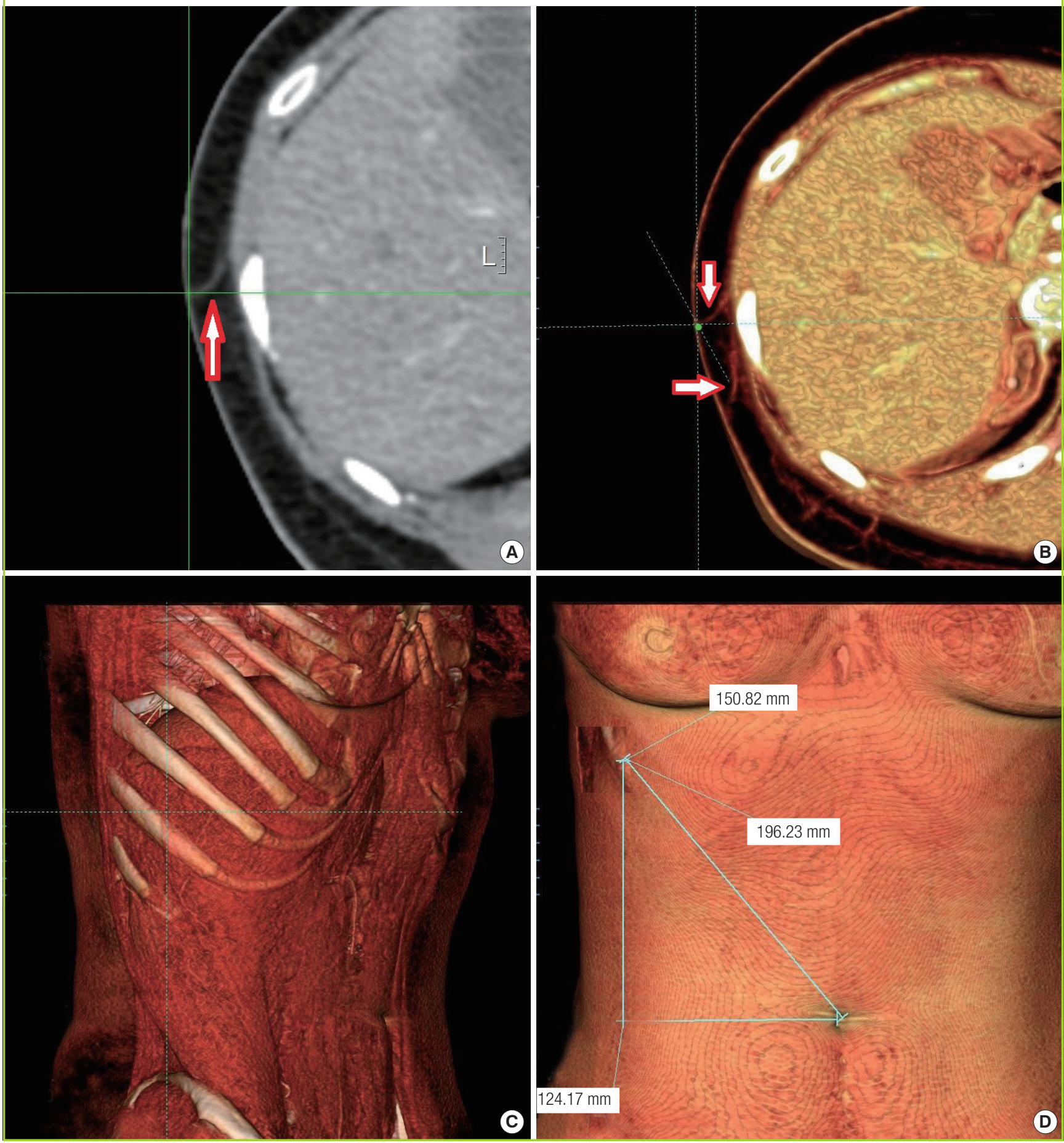
construction in patients with facial soft tissue deficiency.

\section{METHODS}

We conducted a retrospective study of five consecutive patients diagnosed with facial soft tissue deficiency and operated on them between July 2006 and November 2011. The adipofascial flap supplied by the lateral cutaneous branch of the intercostal artery was harvested from the lateral chest as the main pedicle. This flap is similar to the lateral intercostal artery perforator flap, which has been previously used and studied mainly for breast reconstruction [6-11]. Preoperatively, the pedicle integrity was confirmed, and the cutaneous perforator was marked using a hand-held Doppler. In some cases, multidetector computed tomography was performed, the dominant perforator was identified, and the piercing location was measured from the anterior superior iliac spine and from the umbilicus (Fig. 1). We designed the flap to fit the size required at the recipient site. Flap design included the area containing the perforators. A linear incision was made along the rib, which had a vascular main intercostal pedicle. First, we dissected below Scarpa's fascia as the dorsal limit of the flap. Then, the adipofascial flap was elevated from the medial to the lateral side, including the perforator that pierced the serratus anterior muscle after emerging from the costal segment of the lateral intercostal artery. After confirming the location of the perforator, pedicle dissection was performed dorsally (Fig. 2). After retaining sufficient pedicle length, the lateral intercostal artery was ligated, and the flap was elevated. In the event of a discrep-

Fig. 2. Intraoperative photograph of flap harvesting
The adipofascial flap supplied by the lateral intercostal artery perfora-
tor was elevated from the medial to the lateral side, including the
perforator that pierces the serratus anterior muscle after emerging
from the costal segment of the lateral intercostal artery. After confir-
ming the location of the perforator, pedicle (arrow) dissection was
performed dorsally.

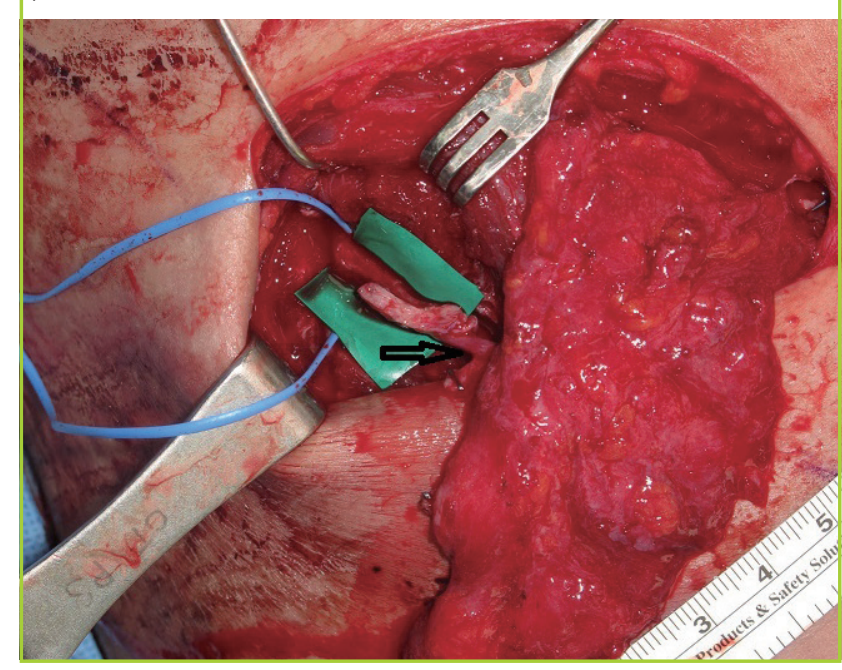

ancy in vessel diameter, we performed anastomosis by placing interrupted sutures farther apart on the larger vessel or using a beveling technique. Once the pedicle was anastomosed to the recipient superficial temporal artery, the harvested flap was inset (Fig. 3). The donor site was closed primarily, and a suction drain was placed (Fig. 4).

\section{RESULTS}

We used lateral intercostal artery perforator-based adipofascial flaps to repair facial soft tissue deficiency associated with ParryRomberg disease or scleroderma. The male-to-female ratio was $2: 3$ (Table 1). The mean age of the patients was 21 years (range, 7-49 years). The seventh or eighth intercostal artery perforators

Fig. 3. Intraoperative photograph of flap anastomosis
Once the pedicle was anastomosed to the recipient superficial temporal
artery, the harvested flap containing the perforator $(\star)$ was inset.

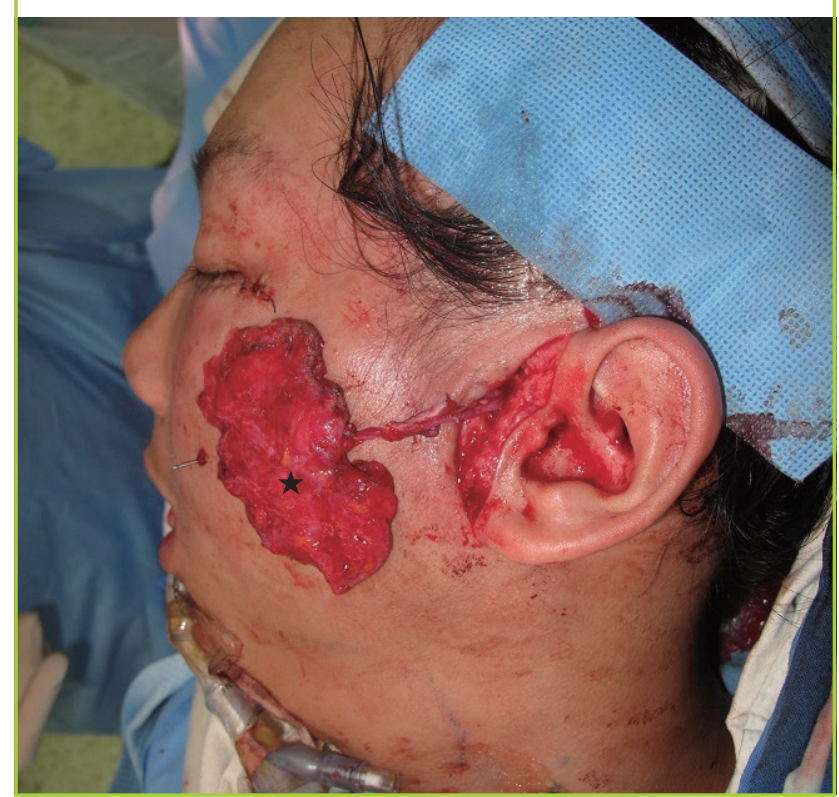

Fig. 4. Postoperative photograph of donor site

The donor site was closed primarily, and a suction drain was placed.

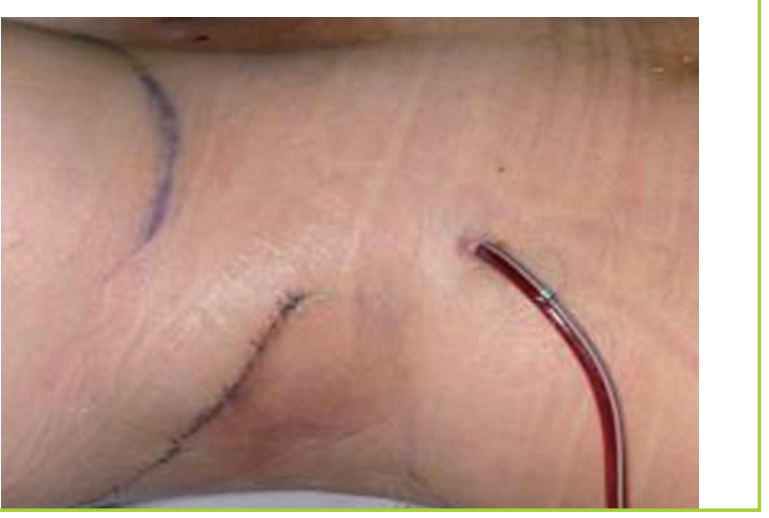


Table 1. Patient characteristics

\begin{tabular}{|c|c|c|c|c|c|c|c|c|c|c|c|}
\hline \multirow[t]{2}{*}{ Patient } & \multirow[t]{2}{*}{ Sex } & \multirow[t]{2}{*}{ Age (yr) } & \multirow{2}{*}{$\begin{array}{l}\text { Flap size } \\
(\mathrm{cm})\end{array}$} & \multirow{2}{*}{$\begin{array}{c}\text { No. of } \\
\text { intercostal } \\
\text { branches }\end{array}$} & \multicolumn{2}{|c|}{$\begin{array}{c}\text { Flap pedicle } \\
\text { diameter (mm) }\end{array}$} & \multirow{2}{*}{$\begin{array}{l}\text { Recipient } \\
\text { site }\end{array}$} & \multirow{2}{*}{$\begin{array}{l}\text { Recipient } \\
\text { artery }\end{array}$} & \multicolumn{2}{|c|}{$\begin{array}{l}\text { Recipient vessel } \\
\text { diameter }(\mathrm{mm})\end{array}$} & \multirow{2}{*}{$\begin{array}{c}\text { Flap pedicle } \\
\text { length }(\mathrm{mm}) \\
\text { Artery } \\
\end{array}$} \\
\hline & & & & & Artery & Vein & & & Artery & Vein & \\
\hline 1 & $\mathrm{~F}$ & 16 & $7 \times 5$ & 8 & 1.3 & 2.4 & Rt. cheek & STA & 2.2 & 3.0 & 63 \\
\hline 2 & $\mathrm{~F}$ & 19 & $10 \times 7$ & 8 & 1.5 & 1.2 & Lt. cheek & STA & 2.0 & 3.2 & 50 \\
\hline 3 & M & 7 & $8 \times 5$ & 7 & 1.5 & 1.5 & Lt. cheek & STA & 1.5 & 1.2 & 67 \\
\hline 4 & M & 14 & $7 \times 3$ & 7 & 1.0 & 1.5 & Lt. cheek & STA & 2.0 & 3.0 & 56 \\
\hline 5 & $\mathrm{~F}$ & 49 & $15 \times 7$ & 8 & 1.5 & 1.3 & Lt. cheek & STA & 2.3 & 3.0 & 71 \\
\hline
\end{tabular}

\section{Fig. 5. A case of adipofascial free flap}

(A) Preoperative photograph of a 14-year-old male patient with progressive hemifacial atrophy on the left side. (B) Postoperative view 1 year after lateral intercostal artery perforator-based adipofascial free flap reconstruction. The asymmetrical facial appearance improved.
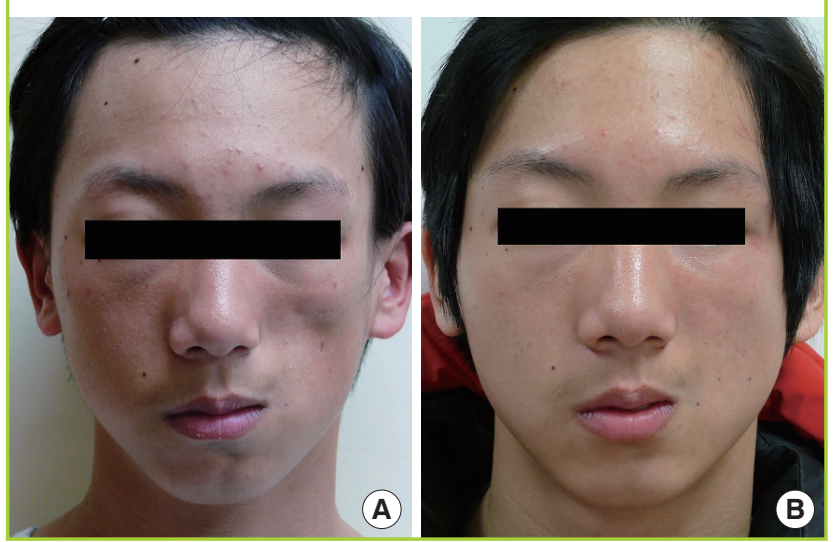

were used for the adipofascial free flap. The pedicle was anastomosed to the recipient vessel, the superficial temporal artery, in all cases. The mean diameter of the pedicle artery was $1.36 \mathrm{~mm}$ (range, $1.0-1.5 \mathrm{~mm}$ ), and the mean pedicle length was $61.4 \mathrm{~mm}$ (range, 50-71 mm). The length was sufficient to perform anastomosis with the superficial temporal vessels. Our largest flap was $15 \mathrm{~cm} \times 7 \mathrm{~cm}$ in size; however, partial fat necrosis occurred in that flap recipient. The thickness of the flaps was approximately 1 to $1.5 \mathrm{~cm}$. No severe complications such as infection, seroma, or hematoma were observed. All of the patients were satisfied with the results.

\section{Cases}

One patient had progressive hemifacial atrophy of the right side. He visited our hospital when he was 14 years old and underwent lateral intercostal artery perforator-based adipofascial free flap reconstruction through a subciliary and preauricular incision. A symmetric appearance was found to have been restored 1 year later (Fig. 5). Another patient with Parry-Romberg disease visited our hospital when he was 7 years old and underwent lateral intercostal artery perforator-based adipofascial free flap

\section{Fig. 6. Case of adipofascial free flap}

(A) Preoperative photograph of a 7-year-old boy with Parry-Romberg disease affecting the left side of his face. He underwent lateral intercostal artery perforator-based adipofascial free flap reconstruction for cheek augmentation. One year later, he developed forehead depression, and dermofat was harvested from the previous surgical site on the chest and grafted to the forehead depression area. (B) Postoperative view 7 years after free flap reconstruction, showing a comparatively symmetrical face.

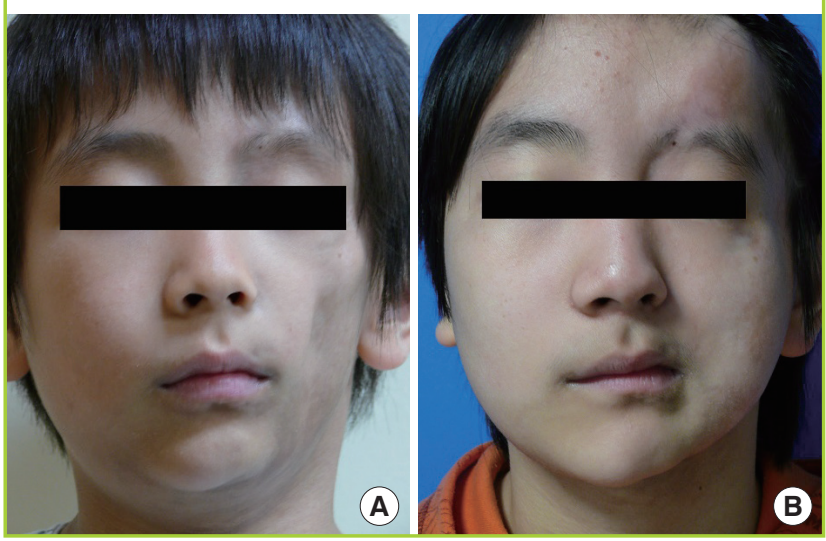

reconstruction for cheek augmentation. One year later, he developed forehead depression. Dermofat was harvested from the previous surgical site on the chest and grafted to the forehead depression area. Six years after the second flap surgery, his face was relatively balanced (Fig. 6). Another patient with scleroderma had cheek depression accompanied by temporal depression. We elevated the adipofascial flap to cover the cheek and temporal depression. This type of flap could also be used for correcting traumatic temporal depression.

\section{DISCUSSION}

Kerrigan and Daniel [4] studied the anatomy and course of the intercostal artery, which links the internal mammary artery with the aorta and forms an arcade. Throughout its course, the intercostal artery forms the vertebral, intercostal, intermuscular, and rectus segments. Among these four segments, the intercostal segment is the longest (approximately $12 \mathrm{~cm}$ ) and gives rise to 5-7 
Fig. 7. Angiography of intercostal artery perforators in a cadaver

Many intercostal artery perforators are apparent, with more than four perforators and the dominant perforators (purple circles) located in the sixth to eighth intercostal spaces (6-8).

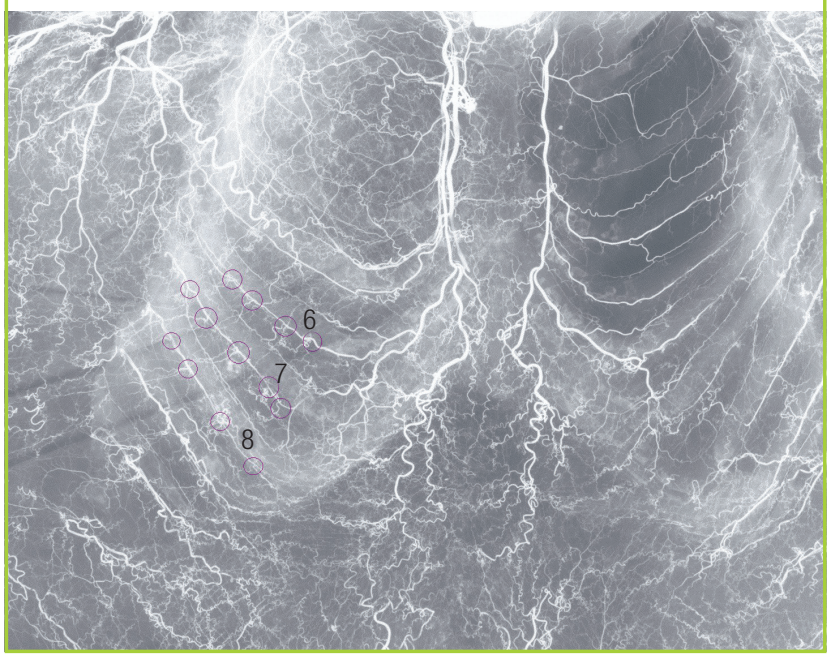

musculocutaneous perforators. The diameter of the dominant intercostal artery perforator is approximately $0.8 \mathrm{~mm}$, which is suitable for microscopic anastomosis. After Kerrigan and Daniel's report, few anatomical studies were published on intercostal artery perforators until Badran et al. [5] conducted a study on dominant perforators arising from the mid-axillary line. Recently, Hamdi et al. [1,2] reported a more detailed study on lateral intercostal artery perforators. They classified these perforators as dorsal, lateral, and anterior artery perforators [2]. Further, they statistically investigated the location of perforators in a cadaveric study $[1]$.

We performed angiography on a fresh cadaver and dissected the lateral intercostal artery perforators in another cadaver. Angiography in a fresh cadaver revealed many intercostal artery perforators, with more than four perforators and the dominant perforators located in the sixth to eighth intercostal spaces (Fig. 7). Two lateral intercostal artery perforator-based adipofascial free flaps were elevated from the cadaver. Through the flap dissection, the pedicle length, diameter, and location of the perforator were evaluated. The pedicle diameters of the two flaps were $1.3 \mathrm{~mm}$ and $1.5 \mathrm{~mm}$ at the origin of the intercostal artery perforator. At the suprafascial plane, the perforator emerged from the serratus anterior muscle, $3 \mathrm{~cm}$ in front of the anterior border of the latissimus dorsi muscle. The pedicle lengths were $52 \mathrm{~mm}$ and $55 \mathrm{~mm}$ from the intercostal muscle fascia, and a further pedicle length of up to $65 \mathrm{~mm}$ was achieved with intercostal muscle dissection.

According to an anatomical study by Hamdi et al. [1], the most reliable perforator of the lateral intercostal artery origi- nated from the sixth intercostal artery. However, we used a flap from the seventh or eighth intercostal artery perforator, as it had sufficient pedicle diameter and length for anastomosis with the superficial temporal artery. Moreover, it may be suitable for anastomosis with the facial artery [13-15]. Badran et al. [5] reported that a single perforator was sufficient to support a flap, even though many donor pedicles from the intercostal artery were available. They were able to elevate flaps as large as $25 \mathrm{~cm} \times 17 \mathrm{~cm}$. In our study, a single pedicle provided sufficient nourishment for the survival of an entire flap. However, multiple pedicles were encountered during flap dissection. If we had inadvertently cut one pedicle, we could have used another.

The largest flap that we used was $15 \mathrm{~cm} \times 7 \mathrm{~cm}$, but it developed partial fat necrosis. Therefore, it appears that an adipofascial flap can be safely elevated at a maximum size of approximately $12 \mathrm{~cm} \times 7 \mathrm{~cm}$; however, additional clinical studies are needed to confirm this observation. We believe that the vertical length of the adipofascial flaps should not exceed $10 \mathrm{~cm}$. If the vertical length of these flaps is greater than this value, the circulation of the skin flap at the donor site may be affected. Although we experienced partial failure with a $15 \mathrm{~cm} \times 7 \mathrm{~cm}$ flap, the donor site healed without problems such as seroma or hematoma [16]. To avoid donor site morbidities, we elevated the adipofascial flap below Scarpa's fascia. No skin necrosis or dehiscence at the flap donor site was observed with this technique, and minimal scarring was observed.

A common procedure for correcting facial depression is fat injection [16-18]. Many plastic surgeons inject free fat at the depression sites, and this procedure is usually repeated multiple times. However, one of our patients with hemifacial atrophy had considerable tissue deficiency, and we could not achieve facial symmetry using fat injections alone. In this case, the lateral intercostal artery perforator-based adipofascial flap was able to cover the volume deficiency. When we needed additional volume support after disease progression, we used dermofat from the previous donor site.

The previous literature concerning intercostal artery flaps mainly described procedures for breast and lower trunk reconstruction [1,6-12]. To the best of our knowledge, despite the multiple benefits of lateral intercostal artery perforator-based adipofascial free flaps in facial reconstruction, no clinical studies on the efficacy of this type of flap have been reported. Various free flaps have been used for facial contour reconstruction, such as groin, omentum, scapular, and parascapular flaps; transverse rectus abdominis muscle flap; radial forearm adipofascial flap; and anterolateral thigh flap [19-24]. However, the lateral intercostal artery perforator-based adipofascial free flap may be the best option in terms of tissue quality, versatility, convenience, 
and decreased morbidity compared with other flaps.

First, the cheek is a commonly involved area of depression, and the texture of the cheek is usually soft. Therefore, a flap with soft texture that does not contain dermis is more suitable for cheek depressions. The lateral intercostal artery perforatorbased free flap has thicker subcutaneous tissue; therefore, substantially more adipose tissue can be harvested compared with that in the case of the groin-free flap or superficial circumflex iliac artery-free flap. The deep inferior epigastric perforator flap has excess adipose tissue and has shown satisfactory results for the correction of facial atrophy [25]. However, defatting evenly in the deep layer is problematic because the pedicle lies in this layer.

Second, a lateral intercostal artery perforator-based free flap has versatility because of its structural composition, which is composed of skin, subcutaneous dermal fat, fascia, and bone. The rib bone may be taken simultaneously, and it may be taken again through the existing scar. The reconstruction of bone as well as that of soft tissue is required in facial asymmetry, and the rib bone is most commonly used for bone graft. If the dermis is required for another area of reconstruction, it can be harvested separately from the flap elevation or can be harvested during a second surgery. Compared with a de-epithelialized flap, the donor site had less tension. Therefore, a dermofat graft can be obtained easily.

Third, harvesting the lateral intercostal artery perforator-based adipofascial free flap for facial reconstruction is convenient. If the pedicle for an anterolateral thigh free flap is a musculocutaneous branch, intramuscular dissection is time consuming because of the thickness of the vastus lateralis muscle. However, since the lateral chest wall has more thin muscle than the thigh, pedicle dissection could be performed with little effort. In addition, as mentioned before, the presence of more than one perforator in this flap afforded the ability to use another perforator if the first was accidentally damaged [5]. Further, the two surgical fields are close to each other, and two surgical teams may approach without changing positions because the location of the lateral intercostal artery flap anterior to that of the thoracodorsal artery perforator flap, latissimus dorsi flap, or scapular or parascapular free flap. Moreover, because the lateral chest wall area has little skin tension, pedicle dissection can be performed through a linear incision with low effort retraction.

Fourth, the lateral intercostal artery perforator-based adipofascial free flap reduces donor-site morbidity. The donor site could be closed without skin tension because we did not remove the skin and the dermis. Therefore, the scars were more cosmetic. Moreover, the lateral chest donor site could be well concealed by wearing a sports bra or swimsuit, making it an even more favorable donor site for cosmetic and reconstructive surgeries. For example, the anterolateral thigh flap inevitably leaves visible depressed scars. The risk of pneumothorax, seroma, and hematoma should be noted. However, the incidence of pneumothorax was very low with careful management, if we did not harvest the rib bone or perform intercostal muscle dissection for pedicle lengthening. Since flap elevation does not disturb axillary lymphatics or involve dissection over a broad area like the latissimus dorsi free flap, the incidence of seroma and hematoma is also anticipated to be low. Furthermore, seroma and hematoma can be prevented by suction drainage and compressive dressing.

However, there are certain disadvantages to the use of lateral intercostal artery perforator-based adipofascial free flaps. In very thin patients, the adipofascial flap may be very difficult to elevate and a flap of sufficient thickness may be difficult to obtain. In such cases, a folded adipofascial flap can be used. Moreover, as the flap cannot be viewed, it is difficult to monitor the flaps. Therefore, the drainage patterns should be carefully assessed.

Facial asymmetry cannot be corrected with single-tissue grafts. Patients with facial asymmetry require a more complete procedure to restore their previous figure. The role of vascularized adipofascial free flaps used in our series is also very important. The utilization of rich vascular tissue from the adipofascial free flap provided the additional effect of restoring texture.

This is the first study on facial contour reconstruction using lateral intercostal artery perforator-based adipofascial free flaps. The use of this type of flap was effective and can be considered a good alternative for restoring facial symmetry in patients with severe facial soft tissue deficiency.

\section{REFERENCES}

1. Hamdi M, Spano A, Van Landuyt K, et al. The lateral intercostal artery perforators: anatomical study and clinical application in breast surgery. Plast Reconstr Surg 2008;121:389-96.

2. Hamdi M, Van Landuyt K, de Frene B, et al. The versatility of the inter-costal artery perforator (ICAP) flaps. J Plast Reconstr Aesthet Surg 2006;59:644-52.

3. Esser JF. Biological or artery flaps of the face. Monaco: Institut Esser de Chirurgie Structive; 1931.

4. Kerrigan CL, Daniel RK. The intercostal flap: an anatomical and hemodynamic approach. Ann Plast Surg 1979;2:411-21.

5. Badran HA, El-Helaly MS, Safe I. The lateral intercostal neurovascular free flap. Plast Reconstr Surg 1984;73:17-26.

6. Daniel RK, Kerrigan CL. Intercostal neurovascular island skin flap. In: Strauch B, Vasconez LO, Hall-Findlay EJ, editors. Grabb's encyclopedia of flaps. 2nd ed. Philadelphia: Lippincott-Raven; 1998. p.1632-5. 
7. Ogawa R, Hyakusoku H, Murakami M, et al. An anatomical and clinical study of the dorsal intercostal cutaneous perforators, and application to free microvascular augmented subdermal vascular network (ma-SVN) flaps. Br J Plast Surg 2002;55:396-401.

8. Kroll SS, Rosenfield L. Perforator-based flaps for low posterior midline defects. Plast Reconstr Surg 1988;81:561-6.

9. Hamdi M, Van Landuyt K, Monstrey S, et al. Pedicled perforator flaps in breast reconstruction: a new concept. Br J Plast Surg 2004;57:531-9.

10. Van Landuyt K, Hamdi M, Blondeel P, et al. Autologous breast augmentation by pedicled perforator flaps. Ann Plast Surg 2004;53:322-7.

11. Bostwick J 3rd, Scheflan M, Nahai F, et al. The "reverse" latissimus dorsi muscle and musculocutaneous flap: anatomical and clinical considerations. Plast Reconstr Surg 1980;65:395-9.

12. Hwang KT, Kim SW, Kim JT, et al. Use of lateral intercostal artery perforator free flaps for resurfacing lower extremities. Ann Plast Surg 2013;71:186-90.

13. Marano SR, Fischer DW, Gaines C, et al. Anatomical study of the superficial temporal artery. Neurosurgery 1985;16: 786-90.

14. Holzle F, Hohlweg-Majert B, Kesting MR, et al. Reverse flow facial artery as recipient vessel for perforator flaps. Microsurgery 2009;29:437-42.

15. Faltaous AA, Yetman RJ. The submental artery flap: an anatomic study. Plast Reconstr Surg 1996;97:56-60.

16. Badran HA, Youssef MK, Shaker AA. Management of facial contour deformities with deepithelialized lateral intercostal free flap. Ann Plast Surg 1996;37:94-101.
17. Myung Y, Lee YH, Chang H. Surgical correction of progressive hemifacial atrophy with onlay bone graft combined with soft tissue augmentation. J Craniofac Surg 2012;23:1841-4.

18. Avelar RL, Goelzer JG, Azambuja FG, et al. Use of autologous fat graft for correction of facial asymmetry stemming from Parry-Romberg syndrome. Oral Surg Oral Med Oral Pathol Oral Radiol Endod 2010;109:e20-5.

19. Harashina T, Nakajima T, Yoshimura Y. A free groin flap reconstruction in progressive facial hemiatrophy. Br J Plast Surg 1977;30:14-6.

20. Wallace JG, Schneider WJ, Brown RG, et al. Reconstruction of hemifacial atrophy with a free flap of omentum. Br J Plast Surg 1979;32:15-8.

21. Upton J, Albin RE, Mulliken JB, et al. The use of scapular and parascapular flaps for cheek reconstruction. Plast Reconstr Surg 1992;90:959-71.

22. Coessens BC, Van Geertruyden JP. Simultaneous bilateral facial reconstruction of a Barraquer-Simons lipodystrophy with free TRAM flaps. Plast Reconstr Surg 1995;95:911-5.

23. Koshy CE, Evans J. Facial contour reconstruction in localised lipodystrophy using free radial forearm adipofascial flaps. Br J Plast Surg 1998;51:499-502.

24. Zhang Q Qiao Q Zhou G, et al. Anterolateral thigh adipofascial flap for correction of facial contour deformities and micromastia. J Reconstr Microsurg 2010;26:341-5.

25. Koshima I, Inagawa K, Urushibara K, et al. Deep inferior epigastric perforator dermal-fat or adiposal flap for correction of craniofacial contour deformities. Plast Reconstr Surg 2000;106:10-5. 